\title{
土壤の周波数依存導電率および比誘電率の二平板電極による測定
}

\author{
学生員 吉村 貴広* 正 員 長岡 直人* \\ 正 員 馬場 吉弘* 正 員 雨谷 昭弘*
}

\section{Measurement of Frequency-Dependent Conductivity and Relative Permittivity of a Soil Using Two Parallel Electrodes}

Takahiro Yoshimura*, Student Member, Naoto Nagaoka*, Member, Yoshihiro Baba*, Member, Akihiro Ametani*, Member

Impedance of cylindrical specimens of a soil having three different lengths is measured at frequencies ranging from $40 \mathrm{~Hz}$ to $40 \mathrm{MHz}$ using two parallel electrodes in order to estimate and remove the effect of the contact impedance. Both conductivity and relative permittivity of the tested soil increase with increasing the moisture ratio. The conductivity of the soil having a moisture ratio of $5 \%$ is almost constant (about $3 \mathrm{mS} / \mathrm{m}$ ) at frequencies lower than $10 \mathrm{MHz}$, and increases with increasing frequency beyond $10 \mathrm{MHz}$. The relative permittivity of the same soil decreases with increasing frequency up to $10 \mathrm{MHz}$, at which it is 7.

キーワード : 導電率, 周波数依存, 接地, 比誘電率, 土䁃

Keywords: conductivity, frequency dependence, grounding, relative permittivity, soil

\section{1. 緒言}

土壌の電気的特性が明らかであれば，FDTD 法等を用い た電磁界解析により, 設備設計時に接地インピーダンスにつ いての定量的な検討が可能となる。文献(1)では, 板状の岩 盤サンプルを平行ストリップ線路に挿入し, 線路方向の電磁 波伝搬速度と減衰定数を測定することによって，13 MHz〜 $550 \mathrm{MHz}$ の周波数範囲における岩盤の導電率と比誘電率を 求めている。13 MHz 以下の範囲においては, 岩盤サンプル の抵抗と静電容量の測定結果からそれらを求めている。電 極と岩盤サンプル間の接触インピーダンスについては, 線 路長および幅が，厚さに比べて充分大きいため，その影響 は小さいものと仮定している。本稿では，二平行平板電極 に土壤サンプルを挟み，電極間距離の異なる 3 ケースで電 極間インピーダンスの周波数特性を測定し，得られた結果 から接触インピーダンスを除去した土潩サンプルの導電率 と比誘電率の周波数特性を算出したので報告する。

\section{2. 測定法と導電率, 比誘電率の算出法}

図 1 に測定回路 ${ }^{(2)}$ を示す。半径 $50 \mathrm{~mm}$ の二平行平板アル ミ電極間に土壇サンプルを挟み, $40 \mathrm{~Hz}$ から $40 \mathrm{MHz}$ の範囲 で電極間のインピーダンス (振幅と位相)をインピーダンス アナライザー (Agilent 4294 A) を用いて測定した。電極間 距離は 18,38 および $58 \mathrm{~mm}$ の 3 ケースとした。電極と土 壤の接触インピーダンスを一定にするため, 測定時には上

\footnotetext{
* 同志社大学工学部電気工学科

干 610-0321 京田辺市多々羅都谷 1-3

Department of Electrical Engineering, Doshisha University

1-3, Miyakodani, Tatara, Kyotanabe 610-0321
}

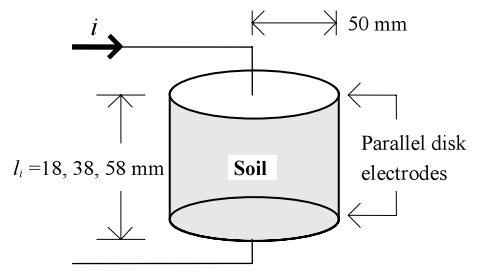

図 1 測定回路図

Fig. 1. A measuring circuit.

部電極板の上に錘を置き, $5.6 \mathrm{kPa}$ で加圧した。土壇サンプ ルは同志社大学京田辺校地リザーブ用地から採取し, 含水率 $\alpha\left(=W_{w} / W_{a} \times 100: W_{w}\right.$ は土壤に含まれる水分の質量, $W_{a}$ は水分も含めた土䁃の全質量）を調整した後測定を行った。 電極間インピーダンス $\dot{Z}_{i}[\Omega]$ は (1) 式によって表される。

$$
\begin{aligned}
\dot{Z}_{i} & =\dot{Z}_{m} l_{i} / S+2 \dot{Z}_{c} / S \\
& =\frac{\operatorname{Re}\left(\dot{Z}_{m}\right)+j \operatorname{Im}\left(\dot{Z}_{m}\right)}{S} l_{i}+2 \frac{\operatorname{Re}\left(\dot{Z}_{c}\right)+j \operatorname{Im}\left(\dot{Z}_{c}\right)}{S}
\end{aligned}
$$

ここで, $\dot{Z}_{m}$ は断面積 $1 \mathrm{~m}^{2}$, 長さ $1 \mathrm{~m}$ あたりの土堙のイン ピーダンス $[\Omega \mathrm{m}], \dot{Z}_{c}$ は断面積 $1 \mathrm{~m}^{2}$ あたりの電極と土壤の 間の接触インピーダンス $\left[\Omega \mathrm{m}^{2}\right], l_{i}$ は電極間距離 $[\mathrm{m}], S$ は 電極面積 $\left[\mathrm{m}^{2}\right]$ である。なお (1) 式において, 上下の電極に おける接触インピーダンは等しいと仮定している。

(1) 式で明らかなように $\dot{Z}_{i}$ の実部と虚部のそれぞれが電極 間距離 $l_{i}$ の一次関数で与えられる。 $l_{i}$ の異なる 3 点 $(N=3)$ の測定結果の実部と虚部のそれぞれに最小二乗法を適用す ることで, $\dot{Z}_{m}[\Omega \mathrm{m}]$ が以下のように求まる。 


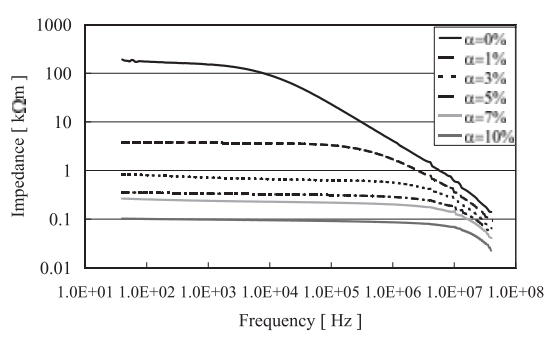

(a) Amplitude, $\left|\dot{Z}_{m}\right|$

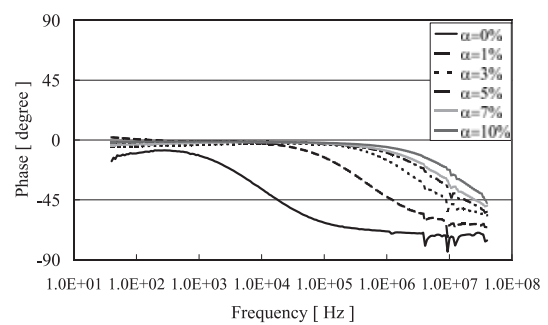

(b) Phase, $\theta_{m}$

図 2 規格化した土䁃インピーダンス $\dot{Z}_{m}$ の周波数特性

Fig. 2. Frequency characteristics of $\dot{Z}_{m}$.

$$
\begin{aligned}
& \operatorname{Re}\left(\dot{Z}_{m}\right)=\frac{N \sum_{i=1}^{N} l_{i} \cdot \operatorname{Re}\left(\dot{Z}_{i}\right)-\sum_{i=1}^{N} l_{i} \cdot \sum_{i=1}^{N} \operatorname{Re}\left(\dot{Z}_{i}\right)}{N \sum_{i=1}^{N} l_{i}^{2}-\left(\sum_{i=1}^{N} l_{i}\right)^{2}} \times S \\
& \operatorname{Im}\left(\dot{Z}_{m}\right)=\frac{N \sum_{i=1}^{N} l_{i} \cdot \operatorname{Im}\left(\dot{Z}_{i}\right)-\sum_{i=1}^{N} l_{i} \cdot \sum_{i=1}^{N} \operatorname{Im}\left(\dot{Z}_{i}\right)}{N \sum_{i=1}^{N} l_{i}^{2}-\left(\sum_{i=1}^{N} l_{i}\right)^{2}} \times S
\end{aligned}
$$

(2) 式より， $\dot{Z}_{m}$ は次式のようにも表される。

$$
\begin{aligned}
& \left|\dot{Z}_{m}\right|=\sqrt{\operatorname{Re}\left(\dot{Z}_{m}\right)^{2}+\operatorname{Im}\left(\dot{Z}_{m}\right)^{2}} \quad[\Omega \mathrm{m}] \\
& \theta_{m}=\frac{180}{\pi} \arctan \frac{\operatorname{Im}\left(\dot{Z}_{m}\right)}{\operatorname{Re}\left(\dot{Z}_{m}\right)} \quad[\mathrm{deg} .]
\end{aligned}
$$

(3) 式より, $\dot{Z}_{m}[\Omega \mathrm{m}]$ の逆数として, 断面積 $1 \mathrm{~m}^{2}$, 長さ $1 \mathrm{~m}$ あたりの土壤のアドミタンス $\dot{Y}_{m}[\mathrm{~S} / \mathrm{m}]$ は次式のように与え られる。

$$
\dot{Y}_{m}=1 / \dot{Z}_{m}=\operatorname{Re}\left(\dot{Y}_{m}\right)+j \operatorname{Im}\left(\dot{Y}_{m}\right) \quad[\mathrm{S} / \mathrm{m}]
$$

一方, 導電率 $\sigma(\omega)$, 比誘電率 $\varepsilon_{r}(\omega)$, 断面積 $S\left[\mathrm{~m}^{2}\right]$, 長さ $l[\mathrm{~m}]$ の均質土壤のアドミタンスは次式で与えられる。

$$
\dot{Y}_{m} S / l=\left[\sigma(\omega)+j \omega \varepsilon_{0} \varepsilon_{r}(\omega)\right] S / l \quad[\mathrm{~S}]
$$

$(4),(5)$ 式より, $\sigma(\omega)$ および $\varepsilon_{r}(\omega)$ は次式のようになる。

$$
\sigma(\omega)=\operatorname{Re}\left[Y_{m}(\omega)\right] \quad[\mathrm{S} / \mathrm{m}], \quad \varepsilon_{r}(\omega)=\operatorname{Im}\left[Y_{m}(\omega)\right] / \varepsilon_{0} \omega
$$

(6) 式の計算を各周波数で行うことにより， $\sigma$ と $\varepsilon_{r}$ の周波 数特性が得られる。

\section{3. 導電率と比誘電率の周波数特性}

電極間インピーダンス $\dot{Z}_{i}$ の測定結果から求めた断面積

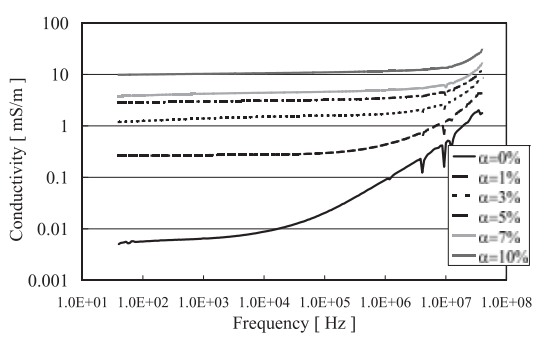

(a) Conductivity, $\sigma$

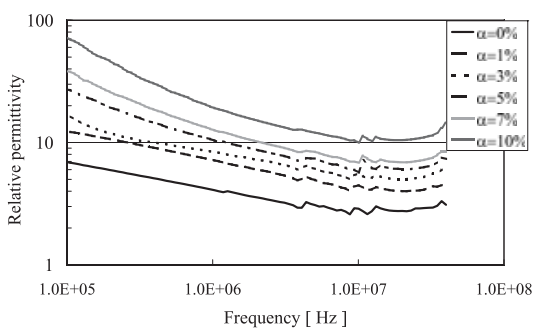

(b) Relative permittivity, $\varepsilon_{r}$

図 3 土壤の導電率 $\sigma$ および比誘電率 $\varepsilon_{r}$ の周波数特性

Fig. 3. Frequency characteristics of $\sigma$ and $\varepsilon_{r}$ of the tested soil.

$1 \mathrm{~m}^{2}$, 長さ $1 \mathrm{~m}$ あたりの土壤インピーダンス $\dot{Z}_{m}$ の周波数 特性を図 2 に示す。 $\dot{Z}_{m}$ は，いずれの含水率 $\alpha$ でも容量性 を示し，低周波領域で一定，高周波領域で約 $20 \mathrm{~dB} / \mathrm{dec}$ の 傾きで周波数の増加に伴い減少している。また, 低周波領 域では $\alpha$ の増加に対してインピーダンスが著しく減少して いる。

算出した導電率 $\sigma$ および比誘電率 $\varepsilon_{r}$ の周波数特性を図 3 に示す。 $\sigma$ は低周波領域で一定で，含水率 $\alpha=1$ および $3 \%$ では高周波領域で周波数の増加に伴い上昇している。低 周波領域では $\alpha$ の増加によって $\sigma$ は著しく上昇している。 周波数 $100 \mathrm{kHz}$ 以下の領域では， $\theta_{m}$ が 0 4 度 [図 2(b) 参照] となり， $\dot{Z}_{m}$ に与える $\varepsilon_{r}$ の寄与分が極めて小さくな り, 精度良く $\varepsilon_{r}$ を算出することが困難であった。このため, $100 \mathrm{kHz}$ 以上のみを表示した。 $\varepsilon_{r}$ は周波数の増加に伴い減 少している。

\section{4. 結言}

二平行平板電極に土壤サンプルを挟み，電極間距離の異 なる 3 ケースで電極間インピーダンスの周波数特性の測定 を行った。得られた結果から, 土壤サンプルの長さに依存 しないと考えられる接触インピーダンス分を除去し, 土畩 サンプルの導電率と比誘電率の周波数特性を算出した。

(平成 18 年 3 月 28 日受付)

$$
\text { 文献 }
$$

(1) Y. Amano and K. Tanabe: "Study on propagation characteristics of electromagnetic wave in underground (I)", CRIEPI Report, No.T89065 (1990) (in Japanese)

天野雄二・田辺一夫：「地盤の電磁波伝搬特性に関する検討 (I)」, 電 力中央研究所報告, No.T89065 (1990)

(2) T. Yoshimura, N. Nagaoka, Y. Baba, and A. Ametani: "Evaluation of parameters of lossy medium for surge analysis of grounding electrodes", IEEJ Trans. PE, Vol.125, No.6, pp.626-627 (2005-6) (in Japanese) 吉村貴広・長岡直人・馬場吉弘・雨谷昭弘：「接地サージ解析のため の損失媒質パラメータ推定」, 電学論 B, 125, 6, pp.625-626 (2005-6) 